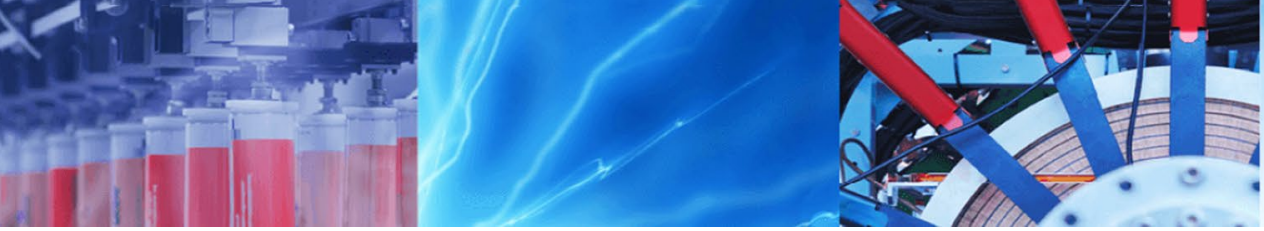

Research Article

\title{
Mechanical, durability and economic performance of concrete incorporating fly ash and recycled aggregates
}

\author{
Muhammad Asad Nawaz ${ }^{1}$ Liaqat Ali Qureshi ${ }^{1,2} \cdot$ Babar Ali $^{2}$ (D) Ali Raza $^{1}$
}

Received: 3 October 2019 / Accepted: 3 January 2020 / Published online: 7 January 2020

(c) Springer Nature Switzerland AG 2020

\begin{abstract}
This paper studies the impact of replacing natural coarse aggregates (NCA) with recycled coarse aggregates (RCA) and cement (OPC) with fly ash (FA), on properties and economy of concrete. RCA was obtained by crushing old concrete specimens. FA of low calcium type was used to partially replace OPC. A total of nine concrete mixes (including a reference mix) were prepared using 50\% RCA, and 100\% RCA with four different levels of FA (0\% FA, 10\% FA, 20\% FA, 30\% FA). Workability, fresh density, compressive strength, apparent porosity, and bulk density was measured to evaluate the performance of each mixture. Mixes with optimum levels of both RCA and FA reaching the compressive strength potential of reference mix at 90 days, were subjected to chloride migration testing. To ascertain the combined impact of RCA and FA on economic and strength performance of concrete, a cost to strength ratio (CSR) analysis was also performed on all mixes. Results of testing indicate that FA compensates the loss in workability of fresh concrete and improve the compressive strength of RCA concrete at 28 and 90 days. Negative influence of RCA on density and porosity is minimized by consumption of FA in concrete. Mixes with 50\% RCA and 20-30\% FA show better resistance against chloride penetration compared to that of the reference mix. CSR analysis suggests that FA must be used along with RCA in concrete in order to minimize the negative influence of RCA on both cost and strength.
\end{abstract}

Keywords Hardened properties · Workability - Economy · Fly ash · Recycled aggregate concrete · Cost to strength ratio · Chloride migration coefficient . Transportation scenario

\section{Introduction}

To minimize the consumption of natural resources of both aggregates and cement industry, waste materials are being encouraged to produce cleaner concrete with lower global warming potential than conventional concrete. It is estimated that in 40 major countries of the world, construction and demolition waste (C\&DW) has reached up to a level of 3 billion tones [1]. Consumption of C\&DW in concrete production has been proved efficient than the practice of backfilling, landfilling, etc. [2, 3].
Higher than ever production rates of cement are causing depletion of natural resources of limestones, clay, shales, etc. Cement industry produces massive amounts of heat and $\mathrm{CO}_{2}$. It is estimated that the cement industry contributes about $7 \%$ of the total anthropogenic $\mathrm{CO}_{2}$ production in the world $[4,5]$. Use of pozzolanic materials in concrete such as FA, granulated blast furnace slags, etc. are being investigated to minimize the production of cement [6]. Pozzolans like FA, and silica fume can improve the durability and long-term mechanical properties of concrete [7-10]. Concrete made with RCA has been proved a weaker and expensive product than the conventional

\footnotetext{
$\triangle$ Babar Ali, babar.ali@scetwah.edu.pk; Muhammad Asad Nawaz, asadkhakhi143@gmail.com; Liaqat Ali Qureshi, Liaqat.qureshi@uettaxila.edu.pk; liaqat.qureshi@scetwah.edu.pk| ${ }^{1}$ Civil Engineering Department, University of Engineering and Technology, Taxila 47050, Pakistan. ${ }^{2}$ Civil Engineering Department, Swedish College of Engineering and Technology, Wah Cantt 47060 , Pakistan.
} 
Table 1 Chemical properties of binders

\begin{tabular}{lllllllllll}
\hline Binder & \multicolumn{8}{l}{ Chemical composition (\%) } \\
\cline { 2 - 9 } & $\mathrm{SiO}_{2}$ & $\mathrm{Al}_{2} \mathrm{O}_{3}$ & $\mathrm{Fe}_{2} \mathrm{O}_{3}$ & $\mathrm{CaO}$ & $\mathrm{MgO}$ & $\mathrm{SO}_{3}$ & $\mathrm{Na}_{2} \mathrm{O}$ & $\mathrm{K}_{2} \mathrm{O}$ & Loss on ignition & Lime reactivity \\
\hline OPC & 23 & 5 & 4 & 62.4 & 2.5 & 2.9 & 0.2 & 1 & 0.64 & 5.8 \\
FA & 61 & 31 & 2.5 & 2.5 & 0.5 & 1.45 & 1.5 & - & 9.1 & $\mathrm{NA}$ \\
\hline
\end{tabular}

Table 2 Physical properties of binders

\begin{tabular}{|c|c|c|c|c|c|c|c|}
\hline \multirow[t]{2}{*}{ Binder } & \multicolumn{7}{|c|}{ Physical properties } \\
\hline & Specific gravity & $\begin{array}{l}\text { Specific surface } \\
\left(\mathrm{m}^{2} / \mathrm{kg}\right)\end{array}$ & Consistency & $\begin{array}{l}\text { Initial setting } \\
\text { time (min) }\end{array}$ & $\begin{array}{l}\text { Final setting } \\
\text { time (min) }\end{array}$ & Soundness (\%) & $\begin{array}{l}\text { 28-days } \\
\text { compressive } \\
\text { strength }\end{array}$ \\
\hline OPC & 3.15 & 325 & $29.25 \%$ & 112 & 256 & 0.102 & 51.24 \\
\hline FA & 2.36 & 418 & - & - & - & 0.045 & - \\
\hline
\end{tabular}

concrete [1, 11-13]. Impact of recycled aggregates on the economy of concrete considering performance of concrete based on strength has been broadly discussed and it was reported that higher production costs were associated with consumptions of RCA in concrete [2, 3, 14-16]. In order to minimize the negative impact of recycled aggregates on strength and durability of concrete, Akhtar et al. [1] reported that 30-50\% recycled aggregates can be used in concrete with supplementary cementitious materials.

The combined influence of FA and RCA on mechanical performance $[17,18]$ and durability [19] of concrete have been investigated, and these studies showed that higher incorporation levels of FA and RCA were detrimental to strength, but FA improves long-term durability performance of concrete.

The economy is an important aspect of concrete, and studies on the investigation of combined economic and strength performance of concrete made with both FA and RCA are very rare. Although studies are available that deal with combined use of FA and RCA on strength and durability of concrete [17, 19, 20], literature on economic impact of using these materials in concrete is very scarce. Therefore, this study not only investigate the combined effect of FA and RCA (of class F type) on strength and durability properties of concrete, but also a detailed economic impact of FA and RCA on concrete considering its strength is presented in this paper. Cost of FA at the consumer's end may be affected by a very high transportation cost. FA is produced as waste, due to its non-availability in most of the regions of a country, transportation may define the final cost of FA. Therefore, two transportation scenarios were considered for FA to conduct economic analysis (a) worst scenario having very high transportation cost (Port Qasim Power Plant Karachi-to-Taxila, Rawalpindi (1440 km), and (b) Most probable scenario having
Table 3 General properties of fine and coarse aggregates

\begin{tabular}{llll}
\hline Property & Fine aggregates & NCA & RCA \\
\hline Max nominal size $(\mathrm{mm})$ & 4.75 & 19.50 & 19.50 \\
Min nominal size $(\mathrm{mm})$ & 0.075 & 4.75 & 4.75 \\
Particle density $\left(\mathrm{kg} / \mathrm{m}^{3}\right)$ & 2670 & 2615 & 2310 \\
SSD water absorption $(\%)$ & 0.89 & 1.25 & 7.12 \\
$10 \%$ Fine value $(\mathrm{kN})$ & - & 161 & 118 \\
Dry rodded density $\left(\mathrm{kg} / \mathrm{m}^{3}\right)$ & 1575 & 1405 & 1321 \\
Fineness Modulus & 2.65 & - & - \\
\hline
\end{tabular}

a normal transportation cost (from Sahiwal Coal Power Plant-Rawalpindi (359 km)).

\section{Materials and methods}

\subsection{Materials}

\subsubsection{Binder (OPC and FA)}

General purpose OPC of 53 grade complying with ASTM C150 [21] was used in this study. FA was obtained from Port Qasim coal power plant (in Karachi, Paksitan). This FA can be classified to F class of coal ash according to ASTM C618 [22]. Chemical and physical properties of both FA and OPC are given in Tables 1 and 2 respectively.

\subsubsection{Aggregates}

Medium sand of Lawrance Pur quarry was used as a fine aggregate in this research. Crushed stone aggregates of Margalla brand were used as NCA in this research. RCA was manually manufactured due to the absence of C\&DW 
recycling plant. General properties of fine and coarse aggregates are given in Table 3.

\subsubsection{Water and admixture}

Tap water free from organic matter was used to prepare all mixes of concrete. Sikament 520, a high range plasticizer and adheres to Type F of admixtures according to ASTM C496 [23] was used in order to maintain constant workability for all mixtures of concrete.

\subsection{Composition of concrete mixes}

A total of nine concrete mixes were prepared using $0 \%$ RCA, 50\% RCA, and 100\% RCA with four different levels of FA ( $0 \%$ FA, $10 \%$ FA, 20\% FA, and 30\% FA). Details and IDs of each mixture are shown in Table 4. The ratio of binder to fine aggregate to coarse aggregate was kept 1:1.5:3. And a constant water-binder ratio of 0.5 was used for all mixes. A slump of $125 \mathrm{~mm}$ was maintained throughout all mixtures using admixture. In mixes with RCA, pre-saturated RCA was used to replace an equal volume of NCA. Details of ingredients in $1 \mathrm{~m}^{3}$ of each mixture are shown in Table 5. All concrete mixes were mixed in a mechanical mixer of $0.15 \mathrm{~m}^{3}$ capacity. First all solid ingredients were mixed for about 3 min then water and plasticizers in required

Table 4 IDs of mixtures

\begin{tabular}{lcccc}
\hline Mix IDs & FA (\%) & OPC (\%) & RCA (\%) & NCA (\%) \\
\hline R0F0 (M30) & 0 & 100 & 0 & 100 \\
R50F0 & 0 & 100 & 0 & 100 \\
R100F0 & 0 & 100 & 0 & 100 \\
R50F10 & 10 & 90 & 50 & 50 \\
R50F20 & 20 & 80 & 50 & 50 \\
R50F30 & 30 & 70 & 50 & 50 \\
R100F10 & 10 & 90 & 100 & 0 \\
R100F20 & 20 & 80 & 100 & 0 \\
R100F30 & 30 & 70 & 100 & 0 \\
\hline
\end{tabular}

amount were added and mixing continued for about the next $4 \mathrm{~min}$.

\subsection{Preparation and testing of specimens}

Slump test following ASTM C143 [24] was conducted in trials immediately after the mixing of concrete, to decide the dosage of plasticizer to achieve an equal level of workability. For compression testing $150 \times 150 \times 150 \mathrm{~mm} 3$ cubes were cast following BS:EN 12390-3 [25] for all mixes. To determine water absorption, bulk density, and apparent porosity of each mixture $100 \mathrm{~mm}$ cubes were cast and these cubes were tested following procedures given under ASTM C642 [26]. The compressive strength of each mixture was measured at the age of 3, 28, and 90 days. Bulk density, water absorption, and apparent porosity were determined at the age of 28 days. Based on the results of compression testing, the mixes which outperformed the reference mix at any age of curing were also subjected to chloride migration test according to NT BUILD [27] at the age of 28 and 90 days. For chloride migration test, concrete discs of $100 \mathrm{~mm}$ Dia x $50 \mathrm{~mm}$ thick were used. To determine each parameter presented in this research paper three replicate specimens of corresponding mixes were tested.

\subsection{Methodology for CSR analysis}

Cost of conventional materials used in this research was obtained from different construction companies in Islamabad, Pakistan and are given in Table 6. Cost of RCA was assessed qualitatively, its cost was taken as the price of poor-quality aggregates available at hands of different crushing plants in Taxila. Original costs of materials were in Rupees per units of both volume $\left(\mathrm{m}^{3}\right)$ and kilograms, but costs were converted into a consistent unit of USD $/ \mathrm{kg}$ using densities of materials, and present US Dollar rates (1PK Rupees $=0.0072$ USD). Cost of transportation of materials was taken as $0.000051 \mathrm{USD} / \mathrm{kg} / \mathrm{km}$ (original 0.008 Rupees $/ \mathrm{kg} / \mathrm{km}$ as per finance division of Government of Pakistan). This transportation cost was somewhat similar
Table 5 Ingredients in $\mathrm{kg}$ under $1 \mathrm{~m}^{3}$ of each mixture

\begin{tabular}{lcrrrrrr}
\hline MIX ID & OPC & \multicolumn{1}{c}{ FA } & Sand & RCA & NCA & SP & Water \\
\hline R0F0 (Ref) & 360 & 0 & 650 & 0 & 1180 & 4.75 & 180 \\
R50F0 & 360 & 0 & 650 & 540 & 590 & 6.32 & 180 \\
R100F0 & 360 & 0 & 650 & 1180 & 0 & 7.15 & 180 \\
R50F10 & 324 & 36 & 650 & 535 & 590 & 6.12 & 180 \\
R50F20 & 288 & 72 & 650 & 535 & 590 & 5.85 & 180 \\
R50F30 & 252 & 108 & 650 & 535 & 590 & 5.65 & 180 \\
R100F10 & 324 & 36 & 650 & 1070 & 0 & 6.85 & 180 \\
R100F20 & 288 & 72 & 650 & 1070 & 0 & 6.55 & 180 \\
R100F30 & 252 & 108 & 650 & 1070 & 0 & 6.35 & 180 \\
\hline
\end{tabular}


Table 6 Unit cost of materials (USD/kg)

\begin{tabular}{|c|c|c|c|c|c|}
\hline \multirow{2}{*}{$\begin{array}{l}\text { Material } \\
\text { OPC }\end{array}$} & \multicolumn{2}{|c|}{ Location of the source of materials } & \multirow{2}{*}{$\begin{array}{l}\text { Distance from } \\
\text { UET Taxila }(\mathrm{km}) \\
10.5\end{array}$} & \multirow{2}{*}{$\begin{array}{l}\text { Cost of material at the } \\
\text { supplier's hand (USD } / \mathrm{kg} \text { ) }\end{array}$} & \multirow{2}{*}{$\begin{array}{l}\text { The total cost of } \\
\text { material at the hand } \\
\text { of the consumer }\end{array}$} \\
\hline & Haripur, KPK & & & & \\
\hline FA & Worst scenario & $\begin{array}{l}\text { Port Qasim Power Plant, } \\
\text { Karachi, Sindh, Pakistan }\end{array}$ & 1440 & 0.0101 & 0.083440 \\
\hline & Most probable scenario & $\begin{array}{l}\text { Sahiwal Coal Power, Plant, } \\
\text { Punjab, Pakistan }\end{array}$ & 439 & 0.0101 & 0.032389 \\
\hline Fine aggregate & \multicolumn{2}{|c|}{ Attock, Lawrance Pur, Pakistan } & 37.5 & 0.0035 & 0.005413 \\
\hline NCA & \multicolumn{2}{|l|}{ Taxila, Pakistan } & 7.8 & 0.0042 & 0.004598 \\
\hline RCA & \multicolumn{2}{|l|}{ Taxila, Pakistan } & 8.5 & 0.0028 & 0.003234 \\
\hline Plasticizer & \multicolumn{2}{|l|}{ Rawalpindi, Pakistan } & 44 & 1.2000 & 1.202244 \\
\hline Water & \multicolumn{2}{|l|}{ Tap Water } & - & 0.0009 & 0.000900 \\
\hline
\end{tabular}

to the cost of transportation in most of the European Countries i.e. $4.88 \times 10^{-5} \mathrm{Euro} / \mathrm{kg} / \mathrm{km}(0.0000553$ USD $/ \mathrm{kg} /$ $\mathrm{km})$ [28].

For FA of class type $F$ based on the source of coal type that is fed to Power Plants (bituminous grade coal), two transportation scenarios were adopted. In the first scenario, Port Qasim Power Plant was chosen which has a very long distance/a very high transportation cost which may be taken as the worst scenario. In the second scenario, Sahiwal Coal Power Plant was chosen which also produces the Class F type of fly ash, because of the source of coal fed to the power plant is bituminous grade. In the second scenario distance is relatively shorter/transportation cost is lower it may be taken as the most probable scenario.

Cost of $1 \mathrm{~m}^{3}$ of each mixture was calculated using the unit cost of materials given in Table 6 and quantities of materials given in Table 5. Then the cost of $1 \mathrm{~m}^{3}$ of each mix was divided by its compressive strength to evaluate CSR at both 28 and 90 days. Concrete mix with lower cost or higher strength would have a low value of CSR, whereas a mix with higher cost/lower cost would have lower CSR.

\section{Results and discussions}

\subsection{Fresh properties}

\subsubsection{Workability}

Results of slump testing without plasticizer (SP) are presented in Fig. 1 with reference to the target slump of $125 \mathrm{~mm}$. The general trend of results indicates that FA improves the workability of concrete, whereas RCA cause reductions in slump. FA reduce the demand of plasticizer in RCA mixes with its every increasing level. The loss in workability of each mix with respect to reference mixture is also illustrated in Fig. 2.

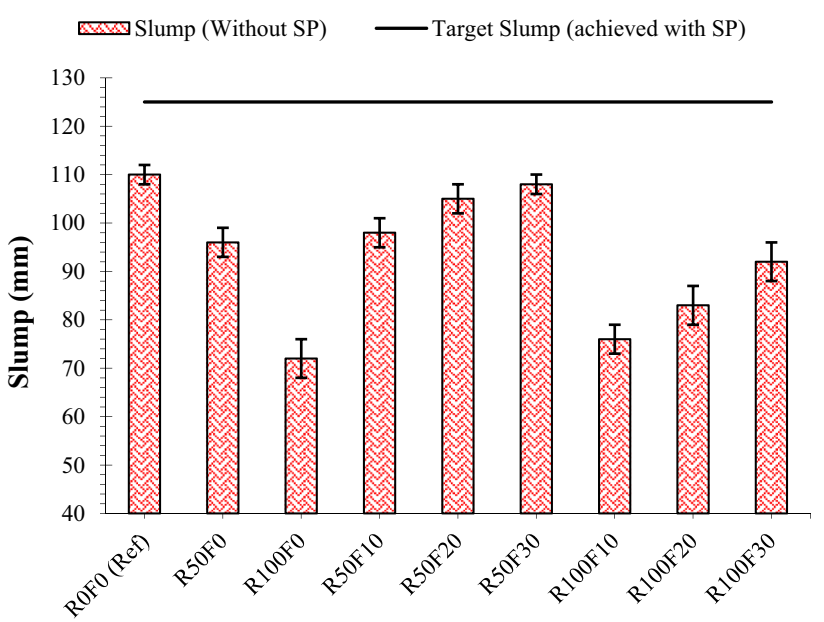

Fig. 1 Results of slump test of all mixes

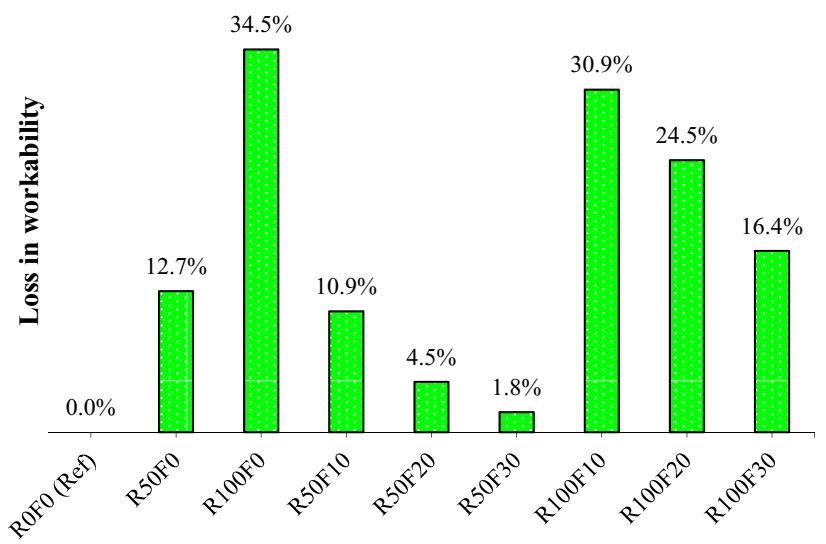

Fig. 2 Loss in workability of each mix with respect to ref mix (without FA and RCA) 
To reach the target slump (achieved with SP) FA reduces the dosage of the plasticizer with each increasing level. Similarly, the mixes with RCA which have a lower level of workability as shown in Fig. 1, also show improvement in workability with increasing level of FA. Although RCA was presoaked in water, irregular shaped particles of RCA reduce the workability of fresh concrete [29]. On the other hand, it is generally considered that FA particles are round and offer lubricating action between harsh particles of concrete. Therefore, FA with increasing level reduces the demand of SP to reach the target slump. Siddique et al., have also reported the positive influence of FA on the workability of concrete [30].

\subsection{Hardened properties}

\subsubsection{Compressive strength}

Results of compression testing are shown in Fig. 2. Relative analysis of results of compression testing is also presented in Table 7. The general trend of results indicates that RCA reduces the compressive strength of concrete by significant margins at all ages of testing. FA introduced some loss in early age strength but improves the later strength of RCA concrete.

The compressive strength of concrete is reduced with each increasing level of RCA in concrete. At $100 \%$ level of $\mathrm{RCA}$, compressive strength of concrete is reduced by $30 \%$ at the age of 28 days. This can be ascribed to the presence of adhered mortar in RCA, which may increase the overall porosity of the concrete. Kurda et al., [17] reported a net decrease of about $14 \%$ at the age of 28 days when they used RCA as coarse aggregates. Poon et al., [31] have also reported significant reductions in compressive strength of concrete when they used RCA as coarse aggregates. These studies have blamed the presence of low-density adhered mortar in RCA for reduction in compressive strength.

FA affects the compressive strength of concrete badly at the early age i.e. at 3 days. But it helps the concrete to gain sufficient strength at 28 and 90 days. The slow pozzolanic reaction of FA particles with $\mathrm{Ca}(\mathrm{OH})_{2}$ (which produced in the hydration of cement) adds to the strength of concrete at later ages. As reported by Hefni et al., [8] compressive strength of concrete is significantly reduced at the age of 3 days, but FA helped concrete to achieve strength higher than that of the conventional concrete at the age of 90 days. Presence of $\mathrm{Ca}(\mathrm{OH})_{2}$ (in a partially hydrated mortar) in RCA make them favorable to be used with FA in concrete. FA had a significant effect on the performance of concrete with both 50\% RCA and 100\% RCA, and strength loss due to the incorporation of RCA is sufficiently recovered at the age of 90 days. Concrete mix having 50\% RCA with both 20\% FA and 30\%FA outperform the conventional concrete at the age of 90 days.

It is worth mentioning here, that mixes with both FA and RCA showed higher rates of strength development between 28 and 90 days. For example, the difference in bar heights at 28 and 90 days is more in mixes with both RCA and FA. This is because FA particles consume the excess $\mathrm{Ca}(\mathrm{OH})_{2}$ present in new and old cement mortars present in concrete and add to the calcium silicate hydrates (CSH) which are durable cementing products [32].

Although none of the mixtures of concrete outperformed reference/control mix at 3 or 28 days, but R50F20, and R50F30 mixes perform almost up to the $100 \%$ level of reference mix at the age of 90 days see Table 7.

\subsubsection{Density}

Surface dried and oven dried density of each mixture is shown in Fig. 4. The general trend of results indicates that FA improves the density of concrete with each increasing level, whereas RCA cause reduction in density.

As the density of RCA is lower than that of the NCA, therefore, reduction in density of concrete was expected. Also, the difference between surface dried and oven dried density of concrete increases as incorporation level of RCA is increased. Which means RCA mixes loss more water upon drying.

Unlike RCA, FA improves the density of concrete with each increasing level. FA helps in recovering the loss in density of concrete due to RCA. FA also reduces the difference between surface dried and oven dried densities of concrete.

Although FA cause significant improvement in the density of RCA concrete mixes, density of concrete mixes did not reach the level of that of conventional concrete. This is because RCA has very low density compared to NCA, as it can be seen in the general properties of aggregates, see Table 3. FA increases the density of concrete by improving its workability. Micro-spherical particles of FA act may act as lubricators to improve the density of concrete under the same compaction energy.

\subsubsection{Apparent porosity}

Apparent porosity of concrete is its very important parameter and it may define the durability of concrete under the influence of chemical solutions [33]. Results of apparent porosity testing are presented in Fig. 5 .

It can be seen in Fig. 5, that RCA increases the apparent porosity of concrete very badly. In the results of density see Fig. 4, it was observed that mixes having RCA showed higher differences in surface dried and oven dried densities. This can be explained as that concrete mixes having 


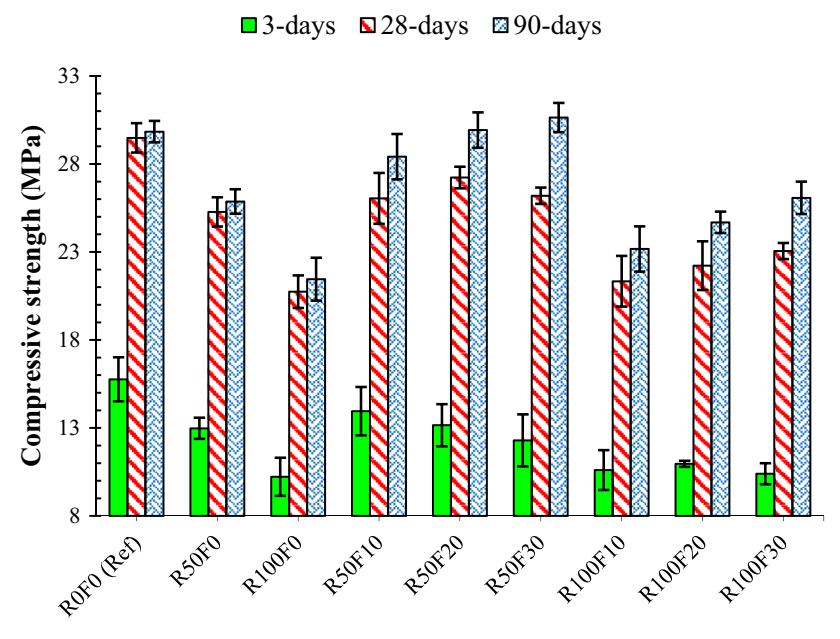

Fig. 3 Results of compression testing of all mixtures at the age of 3, 28 , and 90 days

RCA as coarse aggregate lose more water than that of the mixes with NCA. RCA have more water absorption than NCA, see Table 3. This absorbed water upon drying may increase the porosity of the concrete.

In contrary to RCA, FA reduces the porosity of concrete. Particles of FA are smaller than that of the cement particles (it is evident from the surface area of FA particles which is higher than that of the OPC, see Table 2, higher surface area of particles indicates a higher degree of fineness). FA particles may fill up the micro-voids left between the cement particles, therefore, FA reduces the porosity of concrete. The negative effect of RCA on apparent porosity is also compensated by FA.

\subsubsection{Chloride migration coefficient}

Penetration of chlorides may affect the reinforcement steel in RCC structures. A concrete mix if shows higher resistance against penetration of chlorides is meant to have high durability. Chloride migration test was conducted

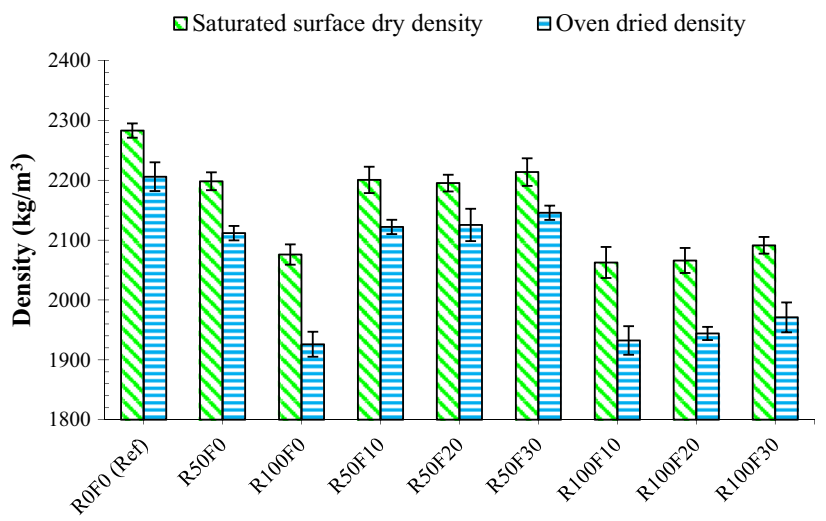

Fig. 4 Results of surface dried and oven dried density of each mixture

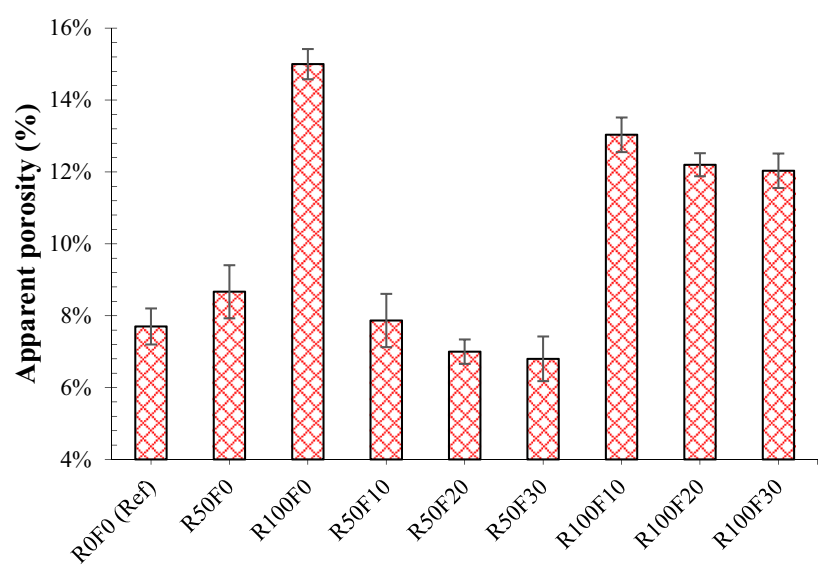

Fig. 5 Apparent porosity of each mixture

on the mixes which reached the potential of reference/ control mix at any age of testing (i.e. 3, 28 and 90 days). Only R50F20, and R50F30 outperformed the conventional concrete at the age of 90 days, see Fig. 3. These mixes were subjected to chloride migration coefficient following the procedures given under NT Build 494 [27]. Coefficient of
Table 7 Relative analysis of results of compression testing, $\mathrm{C}$ : compressive strength

\begin{tabular}{lllllc}
\hline Mix ID & $\begin{array}{l}\mathrm{C}_{3-\text { days }} / \mathrm{C}_{28-\text { days }} \\
(\%)\end{array}$ & $\begin{array}{l}\mathrm{C}_{90 \text {-days }} / \mathrm{C}_{\text {28-days }} \\
(\%)\end{array}$ & $\begin{array}{l}\mathrm{C}_{\text {MIX(3-days) }} / \\
\mathrm{C}_{\text {Ref(3-days) }}(\%)\end{array}$ & $\begin{array}{l}\left.\mathrm{C}_{\text {MIX(28-days) }} / \%\right) \\
\mathrm{C}_{\text {Ref(28-days) }}(\%)\end{array}$ & $\begin{array}{l}\mathrm{C}_{\text {MIX(90-days) }} / \\
\mathrm{C}_{\text {Ref(90-days) }}(\%)\end{array}$ \\
\hline R0F0 (Ref) & 53.5 & 101.2 & 100.0 & 100.0 & 100.0 \\
R50F0 & 51.3 & 102.3 & 82.3 & 85.7 & 86.7 \\
R100F0 & 49.3 & 103.4 & 64.8 & 70.4 & 71.9 \\
R50F10 & 53.6 & 109.1 & 88.5 & 88.3 & 95.2 \\
R50F20 & 48.3 & 109.9 & 83.5 & 92.4 & 100.3 \\
R50F30 & 46.9 & 117.0 & 78.0 & 88.8 & 102.7 \\
R100F10 & 49.7 & 108.6 & 67.3 & 72.4 & 77.7 \\
R100F20 & 49.3 & 111.1 & 69.5 & 75.4 & 82.7 \\
R100F30 & 45.1 & 113.1 & 66.0 & 78.2 & 87.4 \\
\hline
\end{tabular}


migration of mixes was calculated after curing specimens for 28 and 90 days. Results of chloride migration test for selected mixes are shown in Fig. 6.

It is clear from the results of chloride migration coefficient testing, that both RCA mixes with FA outperform reference mixture. Akhtar et al., [1] have reported that FA improves the resistance of concrete against chloride penetration. FA particles improve the resistance of concrete against permeability of chloride ions by virtue of its relatively inert micro-spherical particles. At 90 days chloride migration coefficient of concrete is significantly reduced compared to that of the reference mix. This can be ascribed to the formation of more $\mathrm{CSH}$-gel at the age of 90 days due to the pozzolanic reaction between aluminosilicate

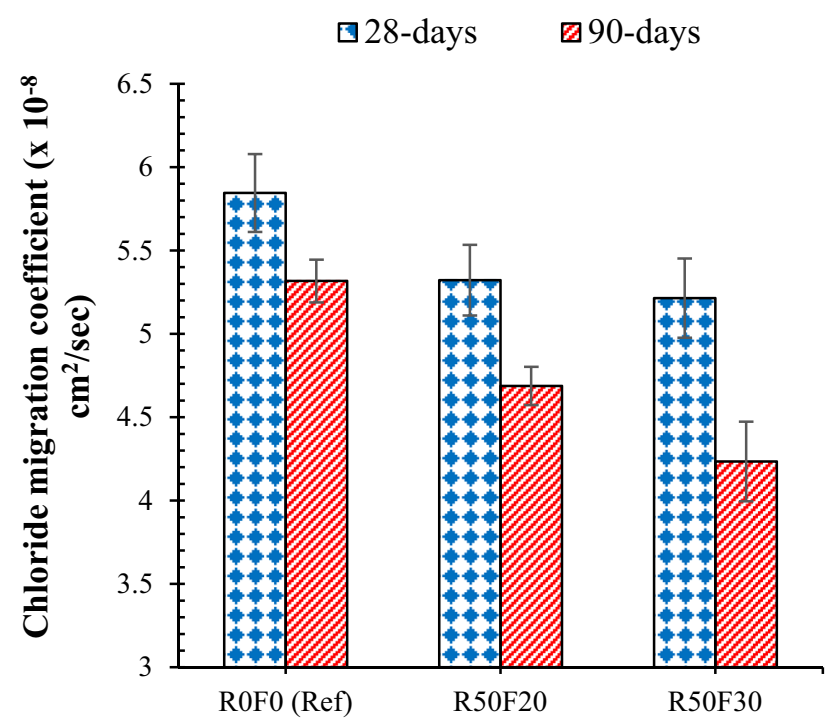

particles of FA and excess $\mathrm{Ca}(\mathrm{OH})_{2}$ present in the cement matrix of concrete.

\subsection{CSR analysis}

For both worst and probable transportation scenario of FA, the cost of $1 \mathrm{~m}^{3}$ of each mix and its ingredients are presented in Table 8. The relative cost of each mixture in both worst and most probable scenario is illustrated in Fig. 7. CSR of each mix at the age of 28 and 90 days is presented in Fig. 8.

\subsubsection{Influence of individual incorporation of RCA on CSR}

From the analysis of costs, it can be seen that RCA does not cause significant changes in the total cost of concrete. At $50 \%$ level of RCA, cost concrete increased by about $0.5 \%$. Although RCA is cheaper than NCA, the total cost of concrete increased because the demand for plasticizer is more in case of mixes with RCA. Cost of plasticizers is nearly 0.6 USD per liter, which is the most expensive ingredient of concrete in the present study. A small increase in the dosage of plasticizer causes a huge surge in the cost of concrete. Another fact which might be blamed for lower reductions in cost upon the inclusion of RCA in place of $\mathrm{NCA}$, is because the major chunk of the total cost is contributed by the binder, see Table 8 .

CSR of mixes with RCA showed that use of RCA is more expensive in terms of cost of strength (USD per unit MPa). RCA mixes showed lower strengths and savings, therefore CSR for mixes involving RCA are way much higher than that of the 'reference mix'. Maximum CSR out of all mixes is for R100F0, see, Fig. 8, which suggest that RCA as a replacement of NCA is not a feasible choice.

Fig. 6 Results of chloride migration coefficient testing

Table 8 Cost of $1 \mathrm{~m}^{3}$ of each mixture and its ingredients

\begin{tabular}{|c|c|c|c|c|c|c|c|c|c|c|}
\hline \multirow[t]{3}{*}{ MIX ID } & \multicolumn{10}{|c|}{ Cost (USD) } \\
\hline & \multirow[t]{2}{*}{ OPC } & \multicolumn{2}{|l|}{ FA } & \multirow[t]{2}{*}{ Sand } & \multirow[t]{2}{*}{ RCA } & \multirow[t]{2}{*}{ NCA } & \multirow[t]{2}{*}{ SP } & \multirow[t]{2}{*}{ Water } & \multicolumn{2}{|l|}{ Total } \\
\hline & & Worst scenario & $\begin{array}{l}\text { Most probable } \\
\text { scenario }\end{array}$ & & & & & & Worst scenario & $\begin{array}{l}\text { Most } \\
\text { probable } \\
\text { scenario }\end{array}$ \\
\hline ROF0 (Ref) & 30.79 & 0.00 & 0.00 & 1.89 & 0.00 & 4.54 & 2.85 & 0.16 & 40.23 & 40.23 \\
\hline R50F0 & 30.79 & 0.00 & 0.00 & 1.89 & 1.51 & 2.27 & 3.79 & 0.16 & 40.42 & 40.42 \\
\hline R100F0 & 30.79 & 0.00 & 0.00 & 1.89 & 3.02 & 0.00 & 4.29 & 0.16 & 40.16 & 40.16 \\
\hline R50F10 & 27.71 & 3.00 & 1.17 & 1.89 & 1.51 & 2.13 & 3.67 & 0.16 & 40.09 & 38.25 \\
\hline R50F20 & 24.63 & 6.01 & 2.33 & 1.89 & 1.51 & 2.13 & 3.51 & 0.16 & 39.85 & 36.17 \\
\hline R50F30 & 21.55 & 9.01 & 3.50 & 1.89 & 1.51 & 2.13 & 3.39 & 0.16 & 39.65 & 34.14 \\
\hline R100F10 & 27.71 & 3.00 & 1.17 & 1.89 & 2.84 & 0.00 & 4.11 & 0.16 & 39.72 & 37.88 \\
\hline R100F20 & 24.63 & 6.01 & 2.33 & 1.89 & 2.84 & 0.00 & 3.93 & 0.16 & 39.47 & 35.79 \\
\hline R100F30 & 21.55 & 9.01 & 3.50 & 1.89 & 2.84 & 0.00 & 3.81 & 0.16 & 39.27 & 33.76 \\
\hline
\end{tabular}




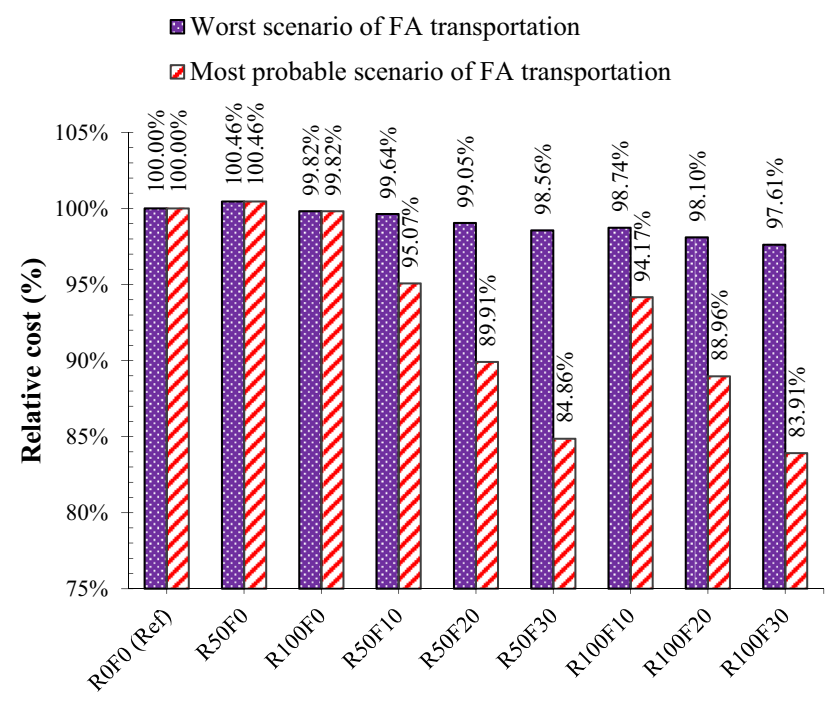

Fig. 7 Cost of each mix with respect to 'reference' mix

\subsubsection{Combined influence of FA and RCA on CSR}

From the analysis of cost, it can be seen that influence of FA on the total cost of concrete is strongly influenced by the transportation scenario. In the case of the worst scenario for transportation of FA, the total cost of concrete slightly reduced by about $1.5 \%$ due to the incorporation of FA. As cost of OPC and FA in the worst scenario are almost same, see Table 6 , so no significant difference is noticed upon the replacement of OPC with FA. On contrary, the total cost of concrete experienced huge savings in case of the most probable scenario. This due to the huge difference in the costs of OPC and FA in case of the most probable scenario.

FA not only reduce the cost of binder but also reduce the consumption of plasticizer in concrete, therefore, despite its higher transportation cost (in worst scenario) FA reduced the cost of concrete more effectively than RCA. In the case of the most probable scenario, FA cause huge reductions in total cost of concrete, see Fig. 7. FA level of $30 \%$ reduces the total cost of concrete by more than $15 \%$. FA also compensates the loss of workability due to RCA. Thus, the negative influence of RCA on the cost of plasticizers is also minimized by FA.

From CSR results, Fig. 8, positively influence of FA on RCA mixes can be noticed that as the percentage of FA increases in concrete, not only the total cost of concrete is reduced but FA also adds to the strength of concrete at both 28 and 90 days. Especially at the age of 90 days, FA reduces the CSR of concrete significantly, this can be ascribed to higher strength gains due to the pozzolanic reaction.

This can be concluded that FA inclusion in RCA mixes bring the huge economy by to concrete at the age of 90 days by reducing CSR, because FA not only reduces cost of binder and plasticizer but also adds sufficient strength to concrete mixes with RCA at 90 days. FA mixes having $100 \%$ RCA also experience reductions in CSR value at both 28 and 90 days. For example, R100F30 in the most probable scenario for transportation of FA outperforms reference mix $\left(\mathrm{CSR}_{\mathrm{R} 100 \mathrm{~F} 30}=1.29<\mathrm{CSR}_{\text {reference }}=1.35\right)$ because of its lower associated value of CSR, see Fig. 8.
Fig. 8 CSR of each mix at the age of 28 and 90 days for both worst and most probable scenario

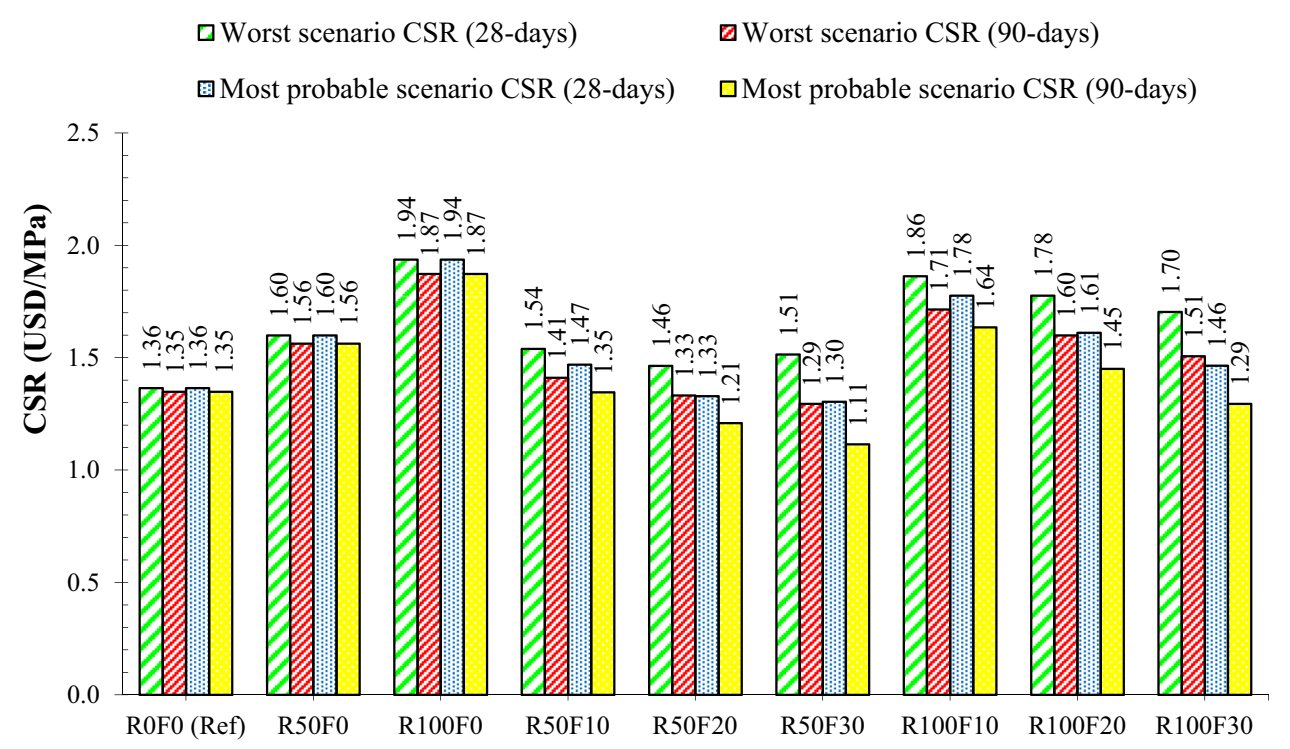




\section{Conclusions}

This paper investigates the combined influence of fly ash and recycled coarse aggregates on the various properties of concrete along with economic performance. Following conclusions can be drawn from this research paper.

\subsection{Fresh properties}

The negative influence of RCA on the workability of concrete is minimized by incorporation of FA. FA not only compensates the loss in workability due to incorporation of RCA, but it also lowers the demand on plasticizers to achieve the required workability. Each increasing level of FA reduces the demand of plasticizer to reach the desired workability.

\subsection{Hardened properties}

It is advised that RCA should be used with FA in order to lower the negative influence of RCA on hardened properties of concrete. RCA influence the compressive strength, density, and porosity of concrete badly with its every increasing level. FA improves the compressive strength of concrete made with RCA especially at 90 days, also FA improves the density of concrete. FA lowers the porosity of RCA concrete and improves its chloride penetration resistance. Considering all the studied hardened properties of concrete made with $50 \%$ RCA and $20-30 \%$ of FA perform almost equal to that of the concrete made with conventional ingredients.

\subsection{CSR analysis}

Based on the equal level of workability for all mixes, RCA does not reduce the total cost of concrete and increases the CSR of concrete compared to conventional concrete. Despite lower costs associated with RCA, the total cost of product concrete is not significantly reduced as demand for plasticizers is increased to maintain workability.

Role of FA on the economy of concrete is governed by its transportation cost. Higher transportation cost does not cause significant savings in total cost of concrete. Savings due to the incorporation of FA increase with decreasing distance between Coal Power Plant and the consumer. FA despite very high transportation cost (distance between consumer and producer $>1400 \mathrm{~km}$ ) still have the potential to improve the economic performance of RCA concrete in terms of CSR (by causing significant improvements in strength). FA not only reduces the total cost with reducing distance between the consumer and producer, but it also causes reductions in demand for plasticizers.

Finally, it can be said that FA positively influence nearly all of the performance indicators of RCA concrete. Conclusions regarding economy analysis should not be generalized, as transportation scenarios, and costs of unit materials may vary in different regions and conditions.

\section{Compliance with ethical standards}

Conflict of interest The authors declare that they have no known competing financial interests or personal relationships that could have appeared to influence the work reported in this paper.

\section{References}

1. Akhtar A, Sarmah AK (2018) Construction and demolition waste generation and properties of recycled aggregate concrete: a global perspective. J Clean Prod 186:262-281

2. Begum RA, Siwar C, Pereira JJ, Jaafar AH (2006) A benefit-cost analysis on the economic feasibility of construction waste minimisation: the case of Malaysia. Resour Conserv Recycl 48:86-98

3. Srour I, Chong WK, Zhang F (2012) Sustainable recycling approach: an understanding of designers' and contractors' recycling responsibilities throughout the life cycle of buildings in two US cities. Sustain Dev 20:350-360

4. Oh D-Y, Noguchi T, Kitagaki R, Park W-J (2014) CO2 emission reduction by reuse of building material waste in the Japanese cement industry. Renew Sustain Energy Rev 38:796-810

5. Flower DJM, Sanjayan JG (2007) Green house gas emissions due to concrete manufacture. Int J Life Cycle Assess 12:282

6. Ali Babar, Qureshi LA (2018) Combined effect of fly ash and glass fibers on mechanical performance of concrete. NED J Res Mech 15:91-100

7. De Gutiérrez RM, Diaz LN, Delvasto S (2005) Effect of pozzolans on the performance of fiber-reinforced mortars. Cem Concr Compos 27:593-598

8. Hefni Y, El Zaher YA, Wahab MA (2018) Influence of activation of fly ash on the mechanical properties of concrete. Constr Build Mater 172:728-734

9. Rashad AM (2015) An exploratory study on high-volume fly ash concrete incorporating silica fume subjected to thermal loads. J Clean Prod 87:735-744

10. Faraj RH, Sherwani AFH, Daraei A (2019) Mechanical, fracture and durability properties of self-compacting high strength concrete containing recycled polypropylene plastic particles. J Build Eng 25:100808. https://doi.org/10.1016/j.jobe.2019.100808

11. Khatib JM (2005) Properties of concrete incorporating fine recycled aggregate. Cem Concr Res 35:763-769

12. Ali B, Qureshi LA (2019) Influence of glass fibers on mechanical and durability performance of concrete with recycled aggregates. Constr Build Mater 228:116783. https://doi.org/10.1016/j. conbuildmat.2019.116783

13. Ali B, Qureshi LA (2019) Durability of recycled aggregate concrete modified with sugarcane molasses. Constr Build Mater 229:116913. https://doi.org/10.1016/j.conbuildmat.2019.116913

14. Coelho A, De Brito J (2013) Economic viability analysis of a construction and demolition waste recycling plant in Portugal-part 
I: location, materials, technology and economic analysis. J Clean Prod 39:338-352

15. Ali B (2019) Effect of aqueous sodium silicate on properties of recycled aggregate mortar. SN Appl Sci 1:1296. https://doi. org/10.1007/s42452-019-1342-2

16. Ali B, Qureshi LA, Baig HS, Malik S, Din M, Aslam HMU (2019) Effect of molasses and water-cement ratio on properties of recycled aggregate concrete. Arab J Sci Eng. https://doi. org/10.1007/s13369-019-04117-w

17. Kurad R, Silvestre JD, de Brito J, Ahmed H (2017) Effect of incorporation of high volume of recycled concrete aggregates and fly ash on the strength and global warming potential of concrete. J Clean Prod 166:485-502

18. Limbachiya M, Meddah MS, Ouchagour Y (2012) Use of recycled concrete aggregate in fly-ash concrete. Constr Build Mater 27:439-449

19. Kurda R, de Brito J, Silvestre JD (2019) Water absorption and electrical resistivity of concrete with recycled concrete aggregates and fly ash. Cem Concr Compos 95:169-182

20. Kou S-C, Poon C (2013) Long-term mechanical and durability properties of recycled aggregate concrete prepared with the incorporation of fly ash. Cem Concr Compos 37:12-19

21. ASTM C150/C150M-18, Standard Specification for Portland Cement, ASTM International, West Conshohocken, PA, 2018, www.astm.org. https://doi.org/10.1520/C0150_C0150M-18

22. ASTM C618-19, Standard Specification for Coal Fly Ash and Raw or Calcined Natural Pozzolan for Use in Concrete, ASTM International, West Conshohocken, PA, 2019, W. astm. or.: No Title

23. ASTM C 494/C494 M-99a, "Standard specification for chemical admixtures for concrete" ASTM International, West Conshohocken, PA, 2015, www.astm.org

24. ASTM C143/C143M-15a, "Standard Test Method for Slump of Hydraulic-Cement Concrete," in ASTM International, West Conshohocken, PA, 2015, www.astm.org
25. BS EN 12390-3, Testing of hardened concrete, Part 3: Compressive Strength of Test Specimens. In: Book of Standards., London Uk (2002)

26. ASTM C642-13, "Standard Test Method for Density, Absorption, and Voids in Hardened Concrete", ASTM International, West Conshohocken, PA, 2013, www.astm.org

27. NT Build 492 - Nordtest Method, "Chloride migration coefficient from non-steadystate migration experiments," in NT Build Book of standards, 1999

28. DELLA, TM, "International Information Services for Truck Transportation. Transportation Prices Europe-Europe", 22 Dec, 2016

29. Poon CS, Shui ZH, Lam L, Fok H, Kou SC (2004) Influence of moisture states of natural and recycled aggregates on the slump and compressive strength of concrete. Cem Concr Res 34:31-36

30. Siddique R (2011) Properties of self-compacting concrete containing class $\mathrm{F}$ fly ash. Mater Des 32:1501-1507

31. Kou SC, Poon CS, Chan D (2007) Influence of fly ash as cement replacement on the properties of recycled aggregate concrete. J Mater Civ Eng 19:709-717

32. Kulkarni N (2015) Evaluation of strength of plain cement concrete with partial replacement of cement by Metakaolin \& Fly Ash. Int J Eng Res Technol 4

33. Papadakis VG, Vayenas CG, Fardis MN (1991) Physical and chemical characteristics affecting the durability of concrete. Mater J 88:186-196

Publisher's Note Springer Nature remains neutral with regard to jurisdictional claims in published maps and institutional affiliations. 